\title{
Novel resistance to imipenem associated with an altered PBP 4 in a Pseudomonas aeruginosa clinical isolate
}

\author{
F. Bellido", C. Veuthey", J. Blasert, A. Bauernfeind ${ }^{c}$ and J. C. Pechère*t \\ -Department of Microbiology, Medical School, University of Geneva, 1211 Geneva 4, \\ Switzerland; 'Department of Internal Medicine, Hospital of Zurich, 8091 Zurich, \\ Switzerland; 'Department of Experimental Medical Microbiology, Max Von \\ Petterkofer-Institut, LM-University, 8000 Munich 2, Federal Republic of Germany
}

\begin{abstract}
A Pseudomonas aeruginasa (isolate 416) from a patient with pneumonia, was initially susceptible to imipenem (MIC: $2 \mathrm{mg} /$ ) but became resistant to this antibiotic (isolate 470, MIC: $32 \mathrm{mg} / \mathrm{l}$ ) during imipenem therapy. Treatment failed. No parallel increases in MIC were observed for other antimicrobials tested. Isolates 416 and $\mathbf{4 7 0}$ shared the same pyocin type and serotype, produced small amounts of an inducible $\beta$-lactamase, and had similar lipopolysaccharide compositions. On electrophoresis of outer membrane proteins, the porin F, identified by the monoclonal antibody MA4 4, was expressed similarly by the two isolates but the production of one band (apparent molecular weight: 47,000) was diminished in isolate 470 . [ ${ }^{4} \mathrm{C}$ ]-Imipenem labelling of intact cells proceded more slowly in 470 than in 416 , especially when bacterial cells were treated by antibody MA4-4 to block the porin $F$ channel. [ ${ }^{\mathrm{H}} \mathrm{C}$ ]Imipenem labelling of penicillin binding proteins (PBP) showed that the band identified as PBP-4 bound markedly less radioactivity in isolate 470 than in 416 . After isolate 470 was passaged several times in antibiotic-free broth, the imipenem MIC was decreased from 32 to $8 \mathrm{mg} /$, and the $\left[{ }^{4} \mathrm{C}\right]$-imipenem PBP pattern recovered the initial profile as exhibited by isolate 416 . Two resistance mechanisms, affecting imipenem electively, could have combined their effect in the post-therapy isolote, altered target protein and reduced permeability.
\end{abstract}

\section{Introduction}

On account of its broad antibacterial spectrum, imipenem has been proposed as monotherapy for treating severe mixed infections (Neu \& Labthavikhul, 1982; Williams 1985; Mayer et al., 1986). However, several recent reports (Quinn et al., 1986; Büscher et al., 1987; Lynch, Drusano \& Mobley, 1987) have documented the emergence of imipenem resistance during imipenem therapy of Pseudomonas aeruginosa infections. Such resistance emerged in six of ten cases of nosocomial pseudomonal pneumonia (Salata et al., 1985). This inconvenience was encountered even though imipenem is thought to overcome $\beta$-lactamase mediated hydrolysis and the permeability barriers of the Gram-negative cell efficiently (Yoshimura, Zalman \& Nikaido, 1983; Yoshimura \& Nikaido, 1985; Hashizume, Yamaguchi \& Sawai, 1986). These are the two major mechanisms of resistance to $\beta$-lactam antibiotics in non-fastidious Gram-negative rods. Notably, altered susceptibility to imipenem generally did not affect the activity of other

\footnotetext{
-Corresponding author.
}

57

$0305-7453 / 90 / 010057+12 \$ 02.00 / 0$

O1990 The British Society for Antimicrobial Chemotherapy 
$\beta$-lactam antibiotics (Quinn et al., 1986; Büscher et al., 1987; Lynch et al., 1987), suggesting a specific resistance mechanism. This appeared to involve the reduced expression of an outer membrane protein thought to provide a specific channel for the penetration of imipenem.

Recently, we have observed the emergence of imipenem resistance, during imipenem therapy, in a case of pseudomonal pneumonia. When we compared pre- and posttherapy strains, the latter exhibited a reduced permeability to imipenem and a decreased expression of the penicillin-binding protein PBP-4. The combination of these two mechanisms is believed to have accounted for the imipenem resistance.

\section{Materials and methods}

\section{Chemicals}

Imipenem and $\left[{ }^{14} \mathrm{C}\right.$-imipenem $(6 \mathrm{mCi} / \mathrm{mmol})$ were kindly supplied by Merck Sharp \& Dohme Research Laboratories, Rahway, New Jersey, USA; [ $\left.{ }^{14} \mathrm{C}\right]$-benzylpenicillin (58.9 $\mathrm{mCi} / \mathrm{mmol}$ ) was purchased from Amersham, Buckinghamshire, England. The other antibiotics were obtained from their respective manufacturers. Solutions of imipenem were freshly prepared on the day of use.

\section{Media}

Mueller-Hinton agar (Oxoid Ltd., Basingstoke, England) was used to determine the MICs and antibiotic Medium 3 (Difco, Detroit, Michigan, USA) was used for $\beta$ lactamase and outer membrane studies.

\section{Determination of MICs}

MICs were determined by an agar dilution method (Ericsson \& Scherris, 1971). The inoculum, $10^{4}-10^{3} \mathrm{cfu}$ per spot, was deposited with a multiple inoculum replicator on to Mueller-Hinton agar containing various concentrations of antibiotics.

\section{Serotyping}

Antisera for the $P$. aeruginosa $O$-serotypes were obtained from rabbits immunized with suspensions of the O-serotype strains that had been heated to $100^{\circ} \mathrm{C}$ for $2 \mathrm{~h}$. Slideagglutination was done with strains pregrown on Trypticase Soy Agar (Difco). The suspension densities were adjusted to $10^{9} \mathrm{cfu} / \mathrm{ml}$ by spectrophotometry (Corning Colorimeter 252, Corning Medical, Halstead, England).

\section{Pyocin typing}

The procedure described by Fyfe, Harris \& Govan (1984) was used.

\section{$\beta$-Lactamase studies}

Crude extracts were prepared by sonication and centrifugation (Marchou et al., 1987). $\beta$-Lactamase activity was measured in a spectrophotometer, using nitrocefin as the substrate (Marchou et al., 1987). $\beta$-Lactamase induction by imipenem $(0.5 \mathrm{mg} / 1$ for $2 \mathrm{~h}$ ) 
was assessed as described by Gootz \& Sanders (1983). One unit of $\beta$-lactamase activity was defined as the amount of enzyme hydrolysing $1 \mu \mathrm{mol}$ of nitrocefin per min at room temperature and $\mathrm{pH} 7.0$, and was standardized against the protein concentration. Bioassay of the imipenem inactivation by crude extracts from induced and non-induced strains was performed on Mueller-Hinton agar plates as described by Levesque, Letarte \& Pechère (1983). The indicator strain was Staphylococcus aureus 209 P, a nonpenicillinase producing strain.

\section{Analysis of outer membrane proteins}

Preparation of cell membranes and outer membrane proteins was performed as described (Marchou et al., 1987). Proteins were separated by discontinuous SDSpolyacrylamide gel electrophoresis (PAGE) (Marchou et al., 1987). Immunoblots were done according to the method of Towbin, Staehelin \& Gordon (1979), using the monoclonal antibody MA4-4 (Mutharia \& Hancock, 1987), which recognizes the porin $F$ of $P$. aeruginosa. This monoclonal antibody was kindly provided by $R$. E. W. Hancock, Vancouver, Canada.

\section{Analysis of lipopolysaccharides (LPS)}

LPS were analyzed by SDS-PAGE, followed by visualization with silver staining as described by Tsai \& Frash (1982). LPS bands were detected by immunoblotting with an acute phase rabbit serum (Tobias, Soldau \& Ulevitch, 1986).

\section{$\left[{ }^{14} \mathrm{C}\right]$-Imipenem uptake of intact cells}

Cells were grown in Antibiotic medium No. 3, harvested in late exponential phase $\left(\mathrm{OD}_{650}: 0-75-0-80\right)$, and suspended in $50 \mathrm{mM}$ phosphate buffer, $\mathrm{pH} 7$ at a density of $30 \mathrm{~g} / \mathrm{ml}$ (wet weight). After the cell suspension had been brought to $25^{\circ} \mathrm{C}$ (requiring a $20 \mathrm{~min}$ equilibrium time), $50 \mu \mathrm{l}$ of $\left[{ }^{14} \mathrm{C}\right.$-labelled imipenem solution $(5 \mathrm{mg} / 1)$ was added to $450 \mu \mathrm{l}$ of bacterial suspension and incubation was maintained at $25^{\circ} \mathrm{C}$ with shaking. At intervals, portions of cell suspensions were rapidly removed and centrifuged $\left(12,000 \mathrm{~g}, 1 \mathrm{~min}, 25^{\circ} \mathrm{C}\right)$, washed in a solution $(1 \mathrm{~g} / \mathrm{l})$ of unlabelled imipenem and finally suspended in $200 \mu \mathrm{l}$ of distilled water. One millilitre of Kontrogel (Kontron, Zurich, Switzerland) was added to each sample, and radioactivity was counted with a scintillation system (model LS-Z500, Beckman Instruments, Inc). Experiments were run with or without addition of the MA4-4 antibody (dilution 1/1000) during the equilibrium time.

\section{Imipenem binding proteins}

Direct binding of $\left[{ }^{14} \mathrm{C}\right]$-imipenem to the inner membrane proteins were analysed as follows. Membrane proteins (c. $200 \mathrm{mg} /$ ) (prepared by the method of Marchou et al., $1987)$ were incubated with $\left[{ }^{14} \mathrm{C}\right]$-imipenem for $10 \mathrm{~min}$ at $30^{\circ}$. Several concentrations of the labelled antibiotic were used $(50-500 \mathrm{mg} / 1)$, and the best result was obtained with $250 \mathrm{mg} / 1(5 \mu \mathrm{Ci} / \mathrm{ml})$. This quite high concentration of $\left[{ }^{14} \mathrm{C}\right]$-imipenem was probably required because of the relatively low radioactivity of our material. Addition of $20 \mu \mathrm{l}$ of unlabelled imipenem $\left(100 \mathrm{mg} / \mathrm{l}\right.$ dissolved in distilled water at $80^{\circ} \mathrm{C}$ and $20 \mu 1$ of $20 \% \mathrm{w} /$ 
v Sarkosyl (sodium lauroyl sarkosinate) for $20 \mathrm{~min}$ at $25^{\circ} \mathrm{C}$ terminated the reaction and solubilized the inner membrane. After centrifugation at $40,000 \mathrm{~g}$ for $30 \mathrm{~min}$ at $10^{\circ} \mathrm{C}$, $100 \mu \mathrm{l}$ of the supernatant was added to $25 \mu \mathrm{l}$ of sample buffer (the same as for the outer membrane preparation) and $6.5 \mu \mathrm{l}$ of $\beta$-mercaptoethanol. Samples were incubated at $80^{\circ} \mathrm{C}$ for $5 \mathrm{~min}$, and $65 \mu \mathrm{l}$ (containing about $70 \mu \mathrm{g}$ of protein) was loaded into the slots of a $7 \cdot 5-12.5 \%$ gradient SDS-PAGE gel. For fluorography, dimethyl sulphoxide impregnated gels were soaked in 2.5-diphenyloxazole-dimethyl sulphoxide $(5 \%$, w/v) for $2 \mathrm{~h}$ and then rehydrated in water for $1 \mathrm{~h}$. Fluograms were obtained after exposure at $-70^{\circ} \mathrm{C}$ for 30 days. Apparent molecular weights of bands were estimated from the corresponding Coomassie Blue-stained gels.

The competition assay between $\left[{ }^{14} \mathrm{C}\right.$-benzylpenicillin (final concentration of $30 \mathrm{mg} /$, $4.9 \mu \mathrm{Ci} / \mathrm{ml})$ with prebound unlabelled imipenem $(5 \mathrm{mg} / \mathrm{l})$ was performed under the same conditions. The concentration of unlabelled imipenem was low enough to avoid the saturation of the PBPs. Membrane fractions were incubated with imipenem for $10 \mathrm{~min}$ at $30^{\circ} \mathrm{C}$ before addition of $\left[{ }^{14} \mathrm{C}\right.$-benzylpenicillin.

\section{Patient and bacteria isolated}

The 56-year-old patient suffering from a post-operative abdominal infection caused by Enterobacter cloacae, enterococci and $P$. aeruginosa, was treated with imipenem alone ( $500 \mathrm{mg}$ every $6 \mathrm{~h}$ as $30 \mathrm{~min}$ infusion). The condition of the patient improved for two days but on the fifth day, the patient became septic and a diffuse pneumonia was apparent from the chest $\mathrm{X}$-rays. Imipenem-resistant $P$. aeruginosa strains were isolated from both the trachea and the wound. Therapy was changed to a combination of tobramycin and piperacillin but the patient died from sepsis a few days later.

\section{Results}

\section{Strain identification}

Among various isolates of $P$. aeruginosa isolated in the patient, pretherapy isolate 416 and post-therapy isolate $\mathbf{4 7 0}$ shared the same identification code (API system, API International S.A., Geneva, Switzerland), were of pyocin type $1 \mathrm{~b}$ and O-serotype 5/16. MICs of a variety of antibiotics (Table I) were identical for isolates 416 and 470 . A notable exception was imipenem, which was less active against isolate 470 (MIC $32 \mathrm{mg} / \mathrm{l}$ against $2 \mathrm{mg} / \mathrm{l}$ for isolate 416 . However, after several passages in antibiotic-free broth, the MIC of imipenem for isolate 470 decreased to $8 \mathrm{mg} / 1$.

\section{$\beta$-Lactamase studies}

Basic and post-induction $\beta$-lactamase production was similar in both isolates (Table II). The bioassay study (Figure 1) showed that, after induction, $\beta$-lactamase of both strains protected the indicator Staphylococcus aureus similarly from the imipenem activity. No protective effect was seen with extracts from uninduced strains.

\section{Outer membrane studies}

On SDS-PAGE of outer membrane proteins, the major change in isolate 470 was decreased expression of a band corresponding to an apparent molecular weight of 
Table I. MICs of antibiotics for isolates 416 and 470

\begin{tabular}{lcc}
\hline & \multicolumn{2}{c}{ MIC (mg/) } \\
Antibiotic & 416 & 470 \\
\hline Imipenem & 2 & 32 \\
Amdinocillin & 512 & 512 \\
Piperacillin & 4 & 4 \\
Carbenicillin & 32 & 32 \\
SCH 34343 & 128 & 128 \\
Ceftazidime & 1 & 1 \\
Cefpirome & 1 & 1 \\
Latamoxef & 8 & 16 \\
CGP 31608 & 4 & 4 \\
BMY 28142 & 1 & 1 \\
Gentamicin & $0-5$ & $0-5$ \\
Amikacin & 1 & 1 \\
Ciprofloxacin & $0-05$ & $0-05$ \\
Pefloxacin & $0-5$ & $0-5$ \\
Chloramphenicol & 64 & 64 \\
Tetracycline & 16 & 16 \\
\hline
\end{tabular}

The imipenem rusceptibility returned to $8 \mathrm{mg} /$ after several mbpassages of the update in broth.

47,000 (Figure 2). This alteration remained when the imipenem MIC decreased from 32 to $8 \mathrm{mg} / \mathrm{l}$ following subpassages (data not shown). The band migrating at a level corresponding to a molecular weight of 35,000 , and recognized as porin $F$ by a Western blot using the MA4-4 antibody (Figure 2) were similar in the pre- and post-therapy isolates. Silver staining of outer membrane preparations (data not shown) displayed similar LPS patterns. $\left[{ }^{14} \mathrm{C}\right]$-Imipenem labelling of the PBPs of intact cells suggesting the existence of an altered permeability in isolate 470 (Figure 3). In the experiments carried out without antiporin MA4-4 antibody (Figure 3(a)), significantly less radioactivity $(P<0.05)$ was bound by cells of isolate 470 than with those from isolate 416 after $0.5 \mathrm{~min}$ of incubation. The differences observed after longer incubation did not achieve statistical significance. When MA4-4 antibody was used to block the porin F channels (Figure 3(b)), the difference between isolates 416 and 470 became obvious $(P<0-05)$ after 1,2 or $3 \mathrm{~min}$ of incubation.

\section{Assay for binding to PBPs}

After staining with Coomassie Blue but before fluography, the electrophoresed inner membrane preparations appeared similar for isolates 416 and 470. Assays performed with $\left[{ }^{14} \mathrm{C}\right.$-imipenem showed six bands, designated A to $\mathrm{F}$ (Figure 4). Using by analogy

Table II. $\beta$-Lactamase activity in isolates 416 and 470

\begin{tabular}{|c|c|c|}
\hline Isolate & $\begin{array}{l}\beta \text {-Lactamase acti } \\
\text { without induction }\end{array}$ & $\begin{array}{l}\mathrm{mU} / \mathrm{mg} \text { protein) } \\
\text { after induction }\end{array}$ \\
\hline $\begin{array}{l}416 \\
470\end{array}$ & $\begin{array}{r}9 \\
12\end{array}$ & $\begin{array}{l}60-3 \\
88.8\end{array}$ \\
\hline
\end{tabular}


F. Bellido et al.

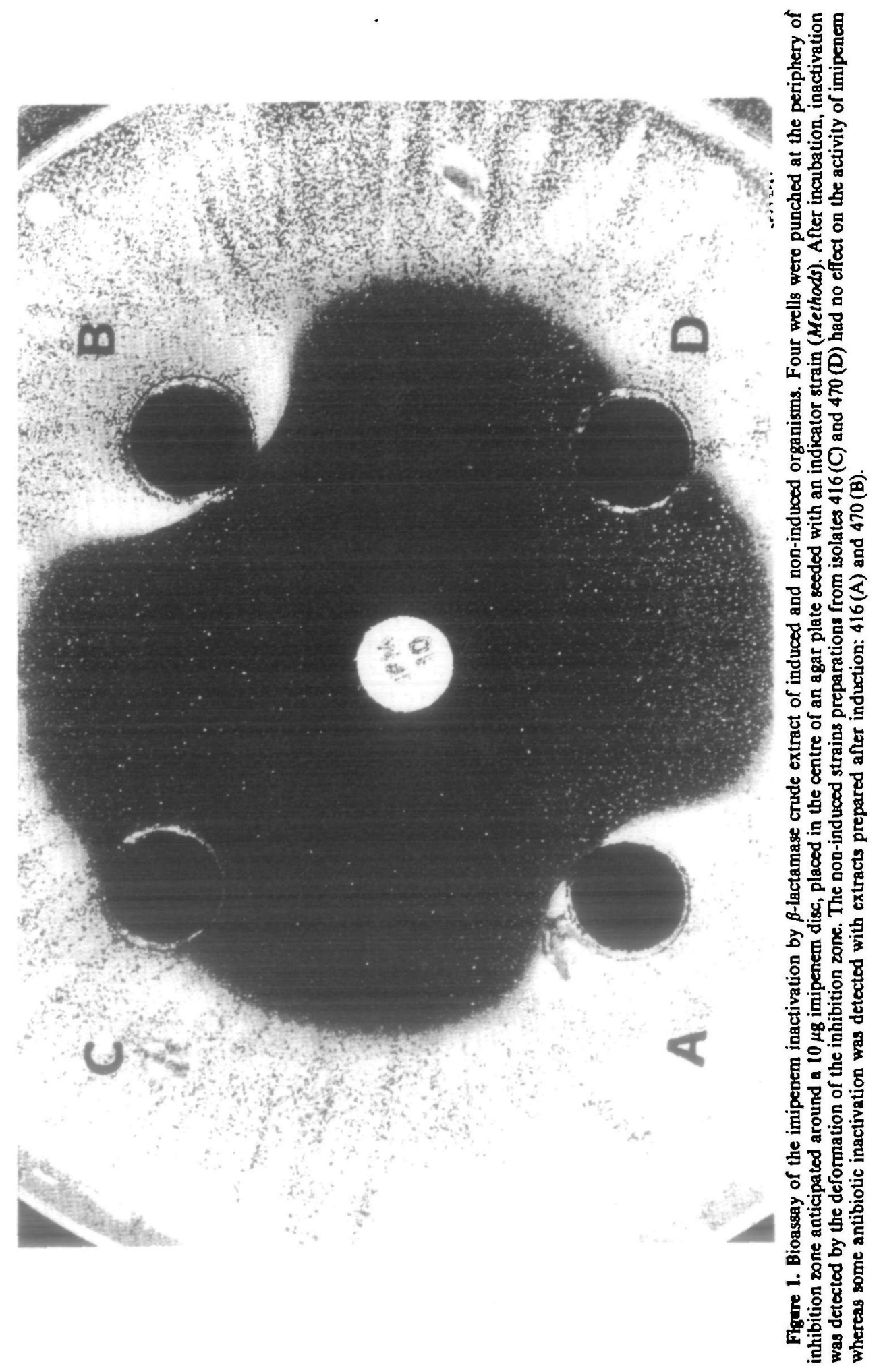




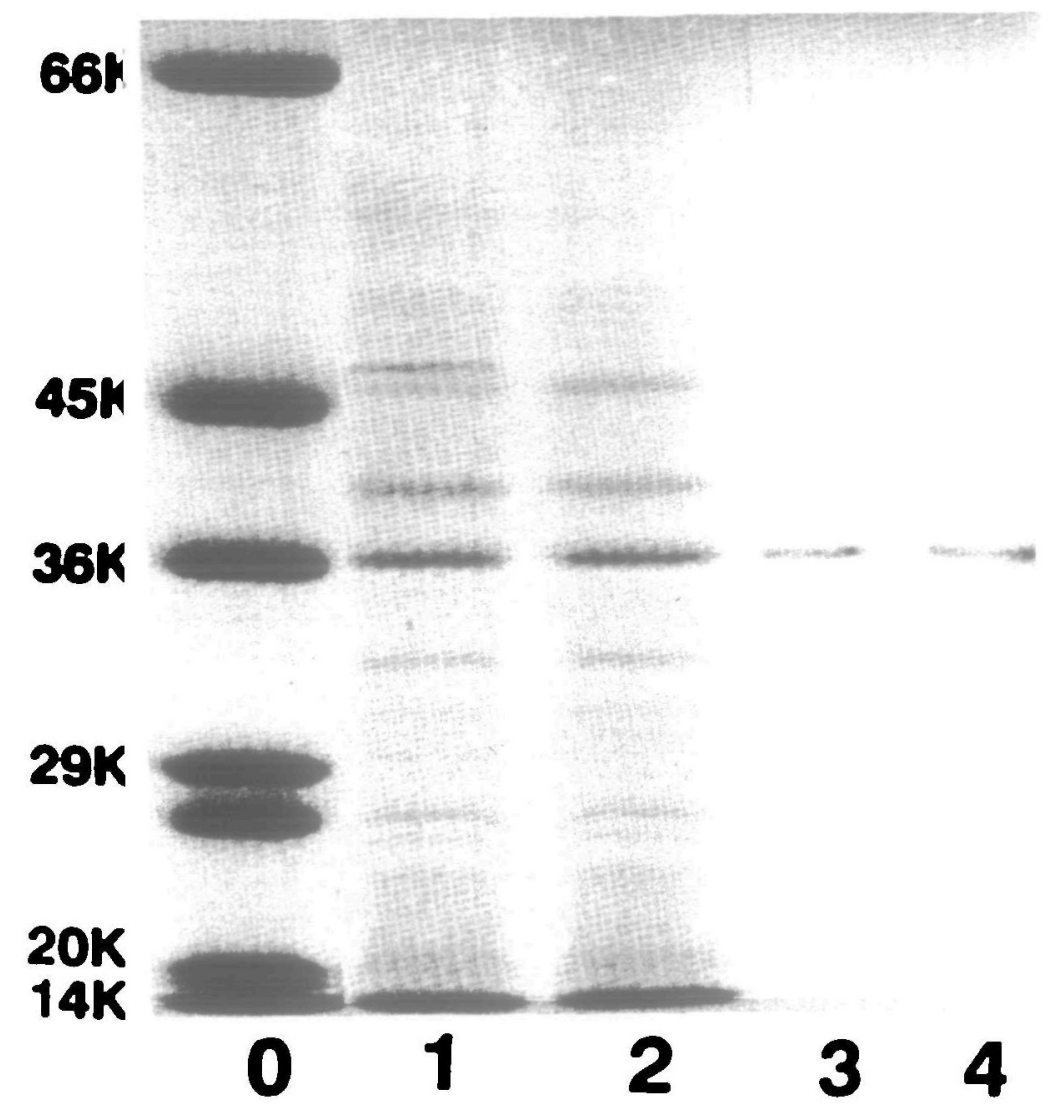

Flgare 2 Outer membrane proteins (OMP) patterns. Lane 0: protein standard with molocular weights as indicated; lane 1: OMPs from isolate 416; lane 2: OMPs from isolate 470; lane 3 and 4: Western blot showing. at molecular weight 35,000 the porin $F$ of isolates 416 and 470 , respectively. A molecular weight 47,000 band seen in the preparation from isolate 416, disappeared in isolate 470 , whereas porin $F$ was expressod similarty in these two strains.

the Spratt's numbering system we classified these bands as A, PBP-la (apparent molecular weight 89,000); B, PBP-1b (82,000); C, PBP-2 (69,000); D, PBP-3 $(55,000)$; E, PBP-4 $(49,000)$; F, PBP-5 $(30,000)$. These apparent molecular weights, calculated from the corresponding Coomassie Blue stained gels, agreed with those previously reported for the PBPs $P$. aeruginosa (Curtis et al., 1979). In the susceptible isolate 416, the three bands (C, E, F) corresponding to the main imipenem targets (PBP-2, PBP-4, PBP-5) were particularly prominent. In the resistant isolate 470 , the band $E(P B P-4)$ was significantly less prominent. The initial prominence of band $\mathrm{E}$ was restored in the organism passaged in antibiotic-free broth. Competition PBP assays of $\left[{ }^{14} \mathrm{C}\right]$-benzylpenicillin with prebound cold imipenem showed, in the resistant isolate 470 , a labelled band (apparent molecular weight, 50,000) that was unseen, presumably because it became saturated with penicillin, in the parent strain (Figure 5).

\section{Discussion}

Natural, non-plasmid mediated, resistance to $\beta$-lactam antibiotic in $P$. aeruginosa, can involve three mechanisms: $\beta$-lactamase-mediated hydrolysis, altered target PBP 


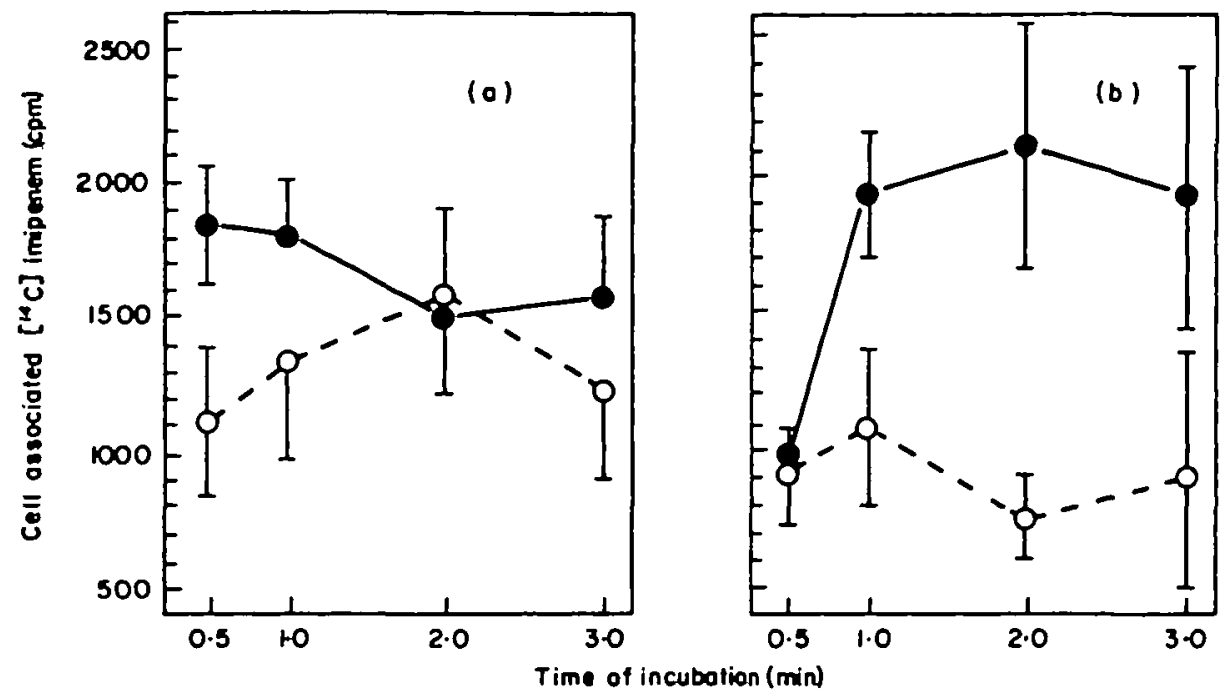

Figure 3. Labelling of intact cells $\left(10^{\circ} \mathrm{cfu} / \mathrm{m}\right)$ with [ [ $\mathrm{C}$-imipenem after different incubation periods, without (a) or after (b) pretreatment with anti-porm $F$ antibody (MA4-4). $\bullet$, Isolate 416; $O$, isolate 470.

molecules and decreased permeability of the outer membrane. The production of a chromosomal type I $\beta$-lactamase was not the cause of imipenem resistance here, as the isolates produced similarly small amounts of $\beta$-lactamase. Although imipenem is considered to be highly resistant to $\beta$-lactamase-mediated hydrolysis (Neu \& Labthavikhul, 1982), our bioassay showed that, after induction, crude extract from either preor post-therapy isolates could impair the activity of the drug. Likewise, it has been reported recently that the self-induced $\beta$-lactamase production decreased imipenem susceptibility of $P$. aeruginosa, although insufficiently to elevate MICs beyond the clinical range (Livermore \& Yang, 1987). Hence, we cannot exclude the possibility that this slow hydrolysis might have facilitated the expression of resistance caused by another mechanism by reducing the number of active antibiotic molecules able to reach the target PBPs.

Previous studies have associated resistance to $\beta$-lactams with modified PBPs in different clinical isolates of $P$. aeruginosa (Godfrey, Bryan \& Rabin, 1981; Mirelman, Nuchamowitz \& Rubinstein, 1981) but these workers did not consider imipenem. In the present investigation autoradiographic data showed an altered interaction of imipenem with PBP-4 in an imipenem-resistant isolate. This change in the PBP pattern is believed to be associated with imipenem resistance, because repeated passages of isolate 470 in antibiotic-free broth were accompanied with partial recovery of initial susceptibility together with restoration of imipenem-binding to PBP-4. Even though previous investigations seemed to indicate a good correlation between the activity of imipenem and its affinity for PBP-2 (Hashizume, Yamaguchi \& Sawai, 1986), the present study showed that PBP-4 had a high binding affinity for imipenem. Moreover, the function of PBP-4 in bacteria other than Escherichia coli is largely unknown and it may be that this target is essential in $P$. aeruginosa. The alteration of PBP -4 could hypothetically involve a decreased affinity for imipenem or the instability of the acylated complex formed between the enzyme and the antibiotic. Here we think that the second possibility was more likely because PBP-4 affinity alterations would probably have decreased the 


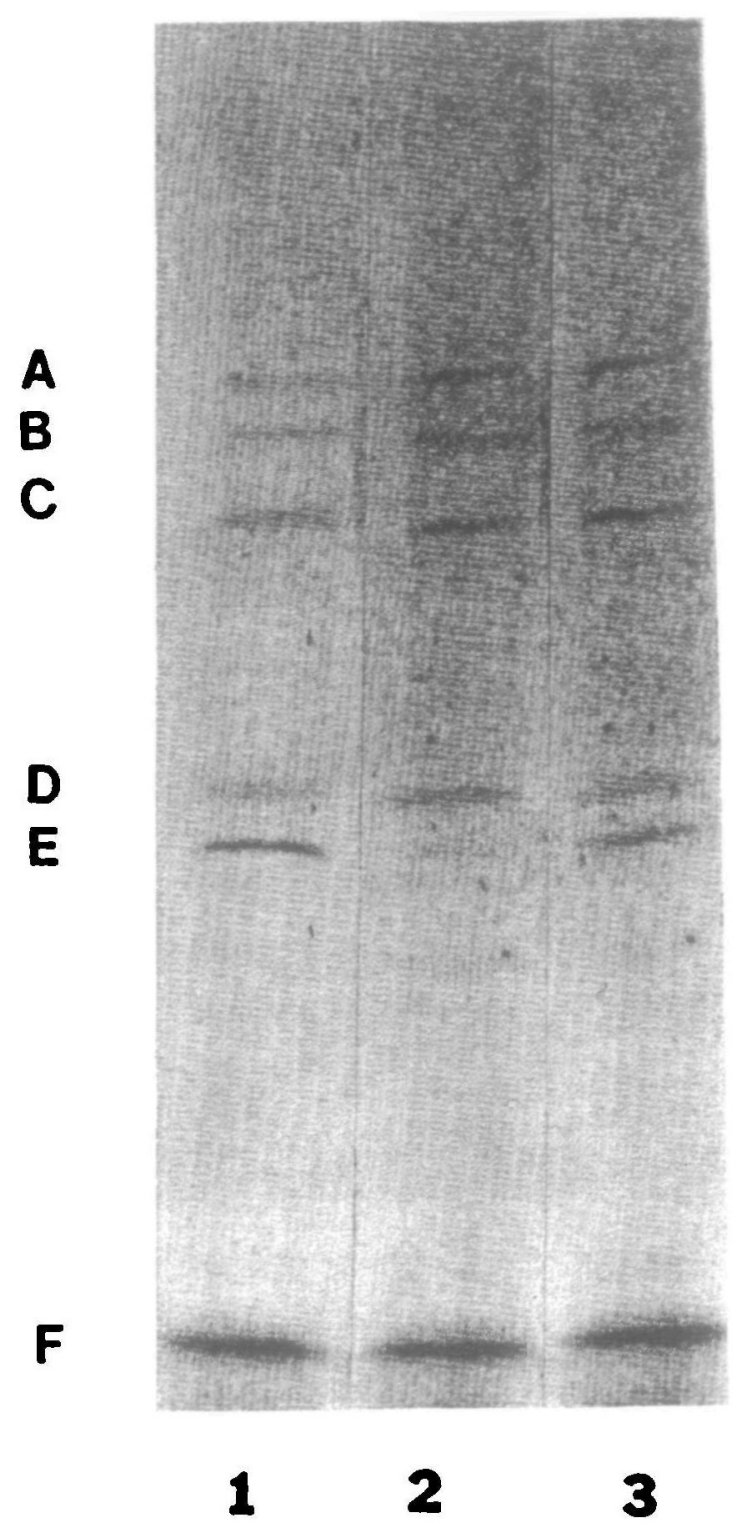

Flgure 4. Binding of [ ${ }^{4} \mathrm{C}$-imipenem to inner membrane proteins: lane 1, isolate 416; lane 2, isolate 470; lane 3. isolate 470 after several paseages in antibiotic-free broth. Letters identify the six imipenem-binding proteins.

susceptibility to other PBP-4-binding $\beta$-lactams such as carbenicillin or the antipseudomonal penem CGP 31608 (Eliopoulos et al., 1987).

The third mechanism by which $P$. aeruginosa can avoid or limit the lethal effects of $\beta$ lactam antibiotics is by reduced outer membrane permeability. Here, as in other investigations (Quinn et al., 1986; Büscher et al., 1987; Lynch et al., 1987), the expression of proteins of $45-49 \mathrm{Kd}$ (the apparent molecular weight varied with the study) was diminished, and the uptake of $\left[{ }^{14} \mathrm{C}\right.$-imipenem (see also Lynch et al., 1987) was altered. Experiments carried out with the antiporin F antibody MA4-4 allowed a 


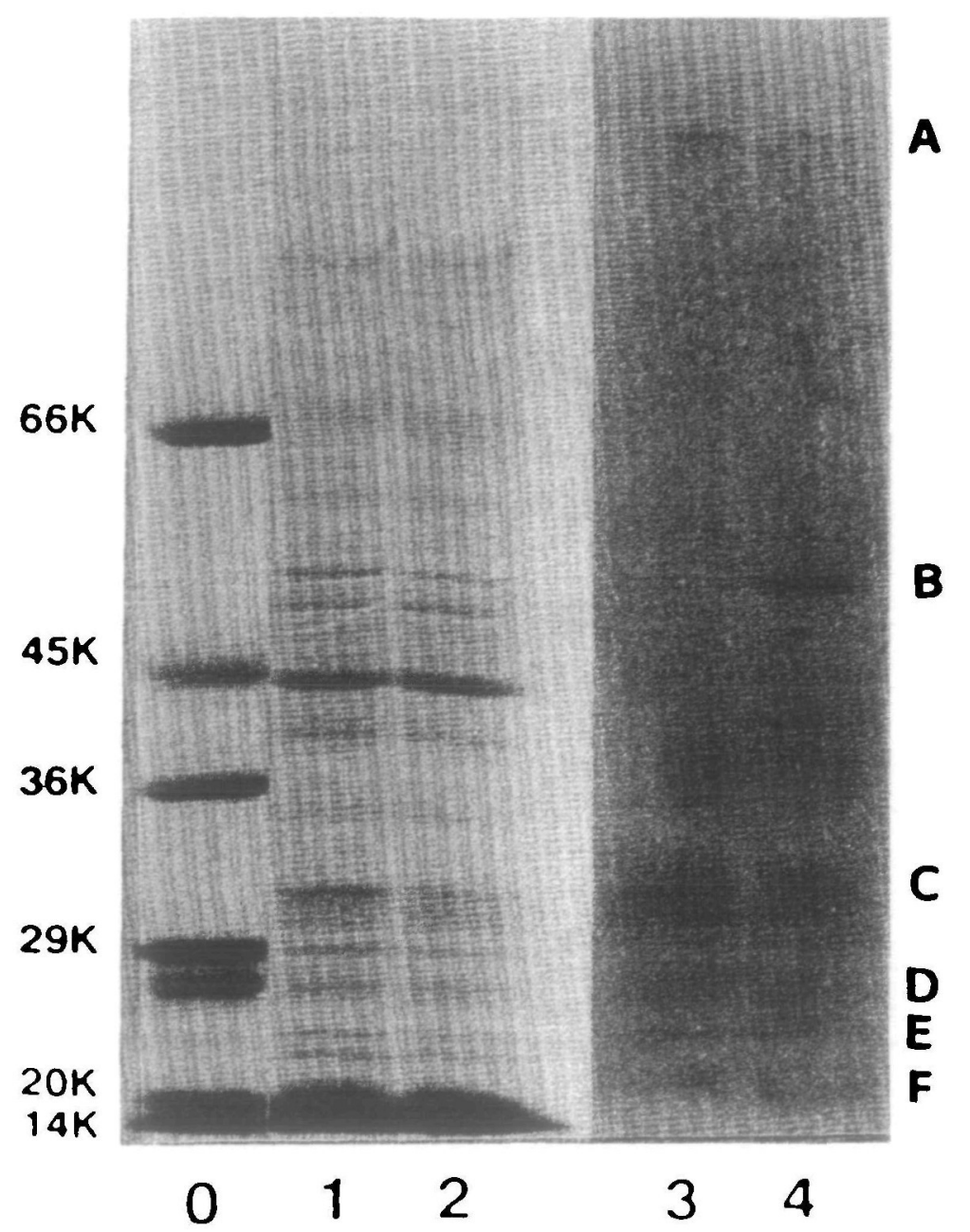

Flgure 5. Competition PBP assays of [ ${ }^{\mathrm{M}} \mathrm{C}$-benzylpenicillin with prebound unlabelled imipenem. Lane O: protein standards; lanes 1 and 2: Coomassie Blue-stained electrophoresis gels of inner membrane proteins of isolates 416 and 470 respectively; lanes 3 and $4:\left[{ }^{4} \mathrm{C}\right.$-benzylpenicillin labelling of PBPs prebound with unlabelled imipenem, in isolates 416 and 470 , respectively. Letters represent the six bands labelled in this assay. Band B (apparent molecular weight, 50,000 ) is not visible in strain 416 (lane 3). These letters do not correspond to those in Figure 4.

better understanding of the routes that imipenem uses for crossing the outer membrane. Since the antigenic epitope of porin F recognized by MA4-4 is destroyed by $\beta$-mercaptoethanol as well as by cleavage of the porin with cyanogen bromide (Mutharia \& Hancock, 1987), we assume that MA4-4 binds to cystein disulphide bond region, which is thought to be located at the internal face of each monomer, according to the model proposed by Moore, Woodruff \& Hancock (1985). Hence MA4-4 is likely to disturb extensively the permeability properties of porin F. MA4-4 antibody altered the imipenem uptake rate, suggesting that imipenem uses the porin $F$ channel, as do most $\beta$-lactam antibiotics (Yoshimura \& Nikaido, 1983; Hancock, 1986, 1987). Experiments using MA4-4 antibody also showed that the imipenem uptake was greatly reduced in 
the molecular weight 47,000 protein-deficient isolate 470 , confirming that this protein was involved in the process of imipenem uptake across the outer membrane.

In conclusion, two mechanisms seemed to have contributed to this emergence of resistance during imipenem therapy. A reduction in permeability increased the MIC of imipenem from 2 to $8 \mathrm{mg} / 1$; and an unstable alteration of PBP-4 seemed associated with a further MIC increase from 8 to $32 \mathrm{mg} /$. The first type of mechanism has been documented several times, but the second one seems novel. However, with the use of new molecules exhibiting, like imipenem, high resistance to $\beta$-lactamases and better ability to penetrate through the outer membrane, it is to be feared that bacteria could develop such mechanisms more often in the future.

\section{Acknowledgements}

This work was supported by the Fonds National Suisse de la Recherche Scientifique (Grant 3-079.087). We are indebted to Catherine Chevrolet and Catherine Cherbulliez for their technical assistance. We thank Dr $\mathrm{H}$. Mett for determining MICs of CGP 31608.

\section{References}

Büscher, K.-H., Cullman, W., Dick, W. \& Opferkuch, W. (1987). Imipenem resistance in Pseudomonas aeruginosa resulting from diminished expression of an outer membrane protein. Antimicrobial Agents and Chemotherapy 31, 703-8.

Curtis, N. A. C., Orr, D., Ross, G. W. \& Boulton, M. G. (1979). Competition of $\beta$-lactam antibiotics for the penicillin-binding proteins of Pseudomonas aeruginosa, Proteus rettgeri and Escherichia coli: comparison with antibacterial activity and effects upon bacterial morphology. Antimicrobial Agents and Chemotherapy 16, 325-8.

Eliopoulos, G. M., Wennersten, C., Reiszner, E. \& Moellering, R. C. (1987). Comparative in vitro activity of CGP 31608, a new penem antibiotic. Antimicrobial Agents and Chemotherapy 31, 1188-93.

Ericsson, H. M. \& Sherris, J. C. (1971). Antibiotic sensitivity testing. Report of an International Collaborative Study. Acta Pathologica et Microblologica Scandinavica, Section B, Suppl. 217. $1-90$.

Fyfe, J. A. M., Harris, G. \& Govan, J. R. W. (1984). Revised pyocin typing method for Pseudomonas aeruginosa. Journal of Clinical Microbiology 20, 47-50.

Godfrey, A. J., Bryan, L. E. \& Rabin, H. R. (1981). B-Lactam-resistant Pseudomanas aeruginosa with modified penicillin-binding proteins emerging during cystic fibrosis treatment. Antimicrobial Agents and Chemotherapy 19, 705-11.

Gootz, T. D. \& Sanders, C. C. (1983). Characterization of $\beta$-lactamase induction in Enterobacter cloacae. Antimicrobial Agents and Chemotherapy 23, 91-7.

Hancock, R. E. W. (1986). Intrinsic antibiotic resistance of Pseudomonas aeruginasa. Journal of Antimicrobial Chemotherapy 18, 653-6.

Hancock, R. E. W. (1987). Role of porins in outer membrane permeability. Journal of Bacteriology 169, 929-33.

Hashizume, T., Ishino, F., Nakagawa, J., Tamaki, S. \& Matsuhashi, M. (1984). Studies on the mechanism of action of imipenem ( $N$-formimidoylthienamycin) in vitro: binding to the penicillin-binding proteins $(\mathrm{PBP})$ in Escherichia coli and Pseudomonas aeruginasa, and inhibition of enzyme activities due to the PBPs in E. coli. Journal of Antibiotics 37, 394-400.

Hashizume, T., Yamaguchi, A. \& Sawai, T. (1986). Outer membrane permeability of imipenem in comparison with other $\beta$-lactam antibiotics. Journal of Antibiotics 39, 153-6.

Levesque, R., Letarte, R. \& Pechere, J. C. (1983). Comparative study of the $\beta$-lactamase activity found in Achromobacter. Canadian Journal of Microbiology 29, 819-26. 
Livermore, D. M. \& Yang, Y. J. (1987). $\beta$-Lactamase lability and inducer power of newer $\beta$ lactam antibiotics in relation to their activity against $\beta$-lactamase-inducibiity mutants of Pseudomonas aeruginosa. Journal of Infectious Diseases 155, 775-82.

Lynch, M. J., Drusano, G. L. \& Mobley, H. L. T. (1987). Emergence of resistance to imipenem in Pseudomonas aeruginosa. Antimicrobial Agents and Chemotherapy 31, 1892-6.

Marchou, B., Bellido, F., Charnas, R., Lucain, C. \& Pechere, J.-C. (1987). Contribution of $\beta$ lactamase hydrolysis and outer membrane permeability to ceftriaxone resistance in Enterobacter cloacae. Antimicrobial Agents and Chemotherapy 31, 1589-95.

Mayer, M., Brand, J., Schlenkhoff, D. \& Opferkuch, W. (1986). Clinical experience with imipenem/cilastatin in the treatment of severe infections in general surgery. Infection 14, Suppl. 2, S160-3.

Mirelman, D., Nuchamowitz, Y. \& Rubinstein, E. (1981). Insensitivity of peptidoglycan biosynthetic reactions of $\beta$-lactam antibiotics in a clinical isolate of Pseudomonas aeruginosa. Antimicrobial Agents and Chemotherapy 19, 687-95.

Moore, R. A., Woodruff, W. A. \& Hencock, R. E. W. (1987). Antibiotic uptake pathways across the outer membrane of Pseudomonas aeruginasa. Antibiotics and Chemotherapy 39, 171-81.

Mutharia, L. M. \& Hancock, R. E. W. (1985). Characterization of two surface-localized antigenic sites on porin protein $\mathrm{F}$ of Pseudomanas aeruginosa. Canadian Journal of Microbiology 31, 381-6.

Neu, H. C. \& Labthavikul, P. (1982). Comparative in vitro activity of $N$ formimidoylthienamycin against Gram-positive and Gram-negative aerobic and anaerobic species and its $\beta$-lactamase stability. Antimicrobial Agents and Chemotherapy 21, 180-7.

Quinn, J. P., Dudeck, E. J., Di Vincenzo, C. A., Lucks, D. A. \& Lerner, S. A. (1986). Emergence of resistance of imipenem during therapy for Pseudomonas aeruginosa infections. Journal of Infectious Diseases 154, 289-94.

Salata, R. A., Gebhart, R. L., Palmer, D. L., Wade, B. H., Scheld, W. M. \& Groschel, D. H. (1985). Pneumonia treated with imipenem/cilastatin. American Journal of Medicine 78, Suppl. 6A, 104-9.

Tobias, P. S., Soldau, K. \& Ulevitch, R. J. (1986). Isolation of lipopolysaccharide-binding acute phase reactant from rabbit serum. Joumal of Experimental Medicine 164, 777-93.

Towbin, H., Staehelin, R. \& Gordon, J. (1979). Electrophoretic transfer of proteins from polyacrylamide gels to nitrocellulose sheets: procedure and some applications. Proceedings of the National Academy of Sciences of the United States of America 76, 4350-4.

Tsai, C. M. \& Frasch, C. E. (1982). A sensitive silver stain for detecting lipopolysaccharides in polyactylamide gels. Analytlcal Biochemistry 119, 115-9.

Williams, J. D. (1985). Activity of imipenem against Pseudomonas and Bacteroides species. Reviews of Infectious Diseases 7, Suppl. 3, S411-6.

Yoshimura, F. \& Nikaido, H. (1985). Diffusion of $\beta$-lactam antibiotics through the porin channels of Escherichia coli K-12. Antimicrobial Agents and Chemotherapy 27, 84-92.

Yoshimura, F., Zalman, L. S. \& Nikaido, H. (1983). Purification and properties of Pseudomonas aeruginosa porin. Journal of Biological Chemistry 258, 2308-14.

(Received S January 1989; revised version accepted 18 August 1989) 